\title{
Proximal femoral fracture surgery in a patient with osteopetrosis tarda: complications and treatment strategy
}

This article was published in the following Dove Press journal:

International Medical Case Reports Journal

I November 2016

Number of times this article has been viewed

\author{
Fırat Seyfettinoglu \\ Ümit Tuhanioğlu \\ Hasan Ulas Ogur \\ Hakan Cicek \\ Department of Trauma and \\ Orthopedics, Adana Numune \\ Training and Educational \\ Hospital, Adana, Turkey
}

Correspondence: Firat Seyfettinoglu Department of Trauma and Orthopedics Adana, Numune Training and Educational Hospital, Serinevler mah, Ege Bagtur Bulvarı, Yüreğir/Adana, Turkey

Tel +90532 716 9721

Fax +903223550155

Email firatseyf@yahoo.com

\begin{abstract}
Osteopetrosis is a rare, inherited disease characterized by defects in osteoclastic function that results in defective bone resorption. When fractures are encountered, fixation is extremely difficult. Osteopetrosis patients have an increased predisposition to infection. If infection develops after a fracture, treatment is more difficult. In this paper, treatment is presented of a 49-year old female to whom proximal femoral nailing was applied for fixation of an osteopetrotic proximal femur fracture; and when it was unsuccessful, revision was made with a locked anatomic plate, which subsequently led to development of infection.
\end{abstract}

Keywords: osteopetrosis, proximal femoral fracture, infection

\section{Introduction}

Osteopetrosis is a rare, inherited disease characterized by defects in osteoclastic function that results in defective bone resorption. ${ }^{1}$ Clinically, it is characterized by dense, sclerotic, and deformed bones. ${ }^{1,2}$ The fragility of dense, sclerotic bones leads to an increased incidence of fractures. ${ }^{3}$ The fractures most frequently involve the upper one-third of the femur and the tibia. ${ }^{3}$ Osteopetrosis tarda, which is also known as marble bone disease, is a subtype of autosomal dominant osteopetrosis type II. ${ }^{4,5}$ It is characterized by clinically minor trauma-related fractures and typical radiographic findings of failure of tubulation and a "bone within a bone" appearance. In the past, different treatment modalities have been attempted, but the ideal implant for the treatment of subtrochanteric fractures with osteopetrosis is still a matter for discussion. ${ }^{4-8}$ Internal fixation can be applied, although technical challenges may be experienced due to increased bone density. As in other fractures, nonunion or varus malunion of these fractures may occur. Although rare, osteopetrosis may complicate the treatment of fractures in such patients. The predisposition to infection is increased in patients with osteopetrosis. Infection together with a fracture makes diagnosis and treatment more difficult. ${ }^{9,10}$ Literature related to the treatment of osteopetrosis-related fractures is generally in the form of case reports.

The aim of this paper was to present the difficulties and points requiring attention during the treatment of a patient with osteopetrosis tarda who developed infection following revision surgery for unsuccessful fixation with proximal femoral nailing $(\mathrm{PFN})$ of a fracture in the proximal femur.

\section{Case presentation}

A 49-year old female patient presented at the emergency department with complaints of pain, sensitivity, and deformity in the left hip following a simple fall at home. From 
the history, it was learned that the patient had osteopetrosis tarda and had not previously had any fractures. Physical examination revealed that there were abduction and external rotation deformity in the left lower extremity and pain on palpation in the hip. On direct radiography, a subtrochanteric femur fracture was determined (Figure 1). Apart from mild anemia, other laboratory test results were normal. The patient was admitted to our clinic for planned surgical treatment of intramedullary PFN. Under general anesthesia, the patient was placed into the right decubitus position and the left lower extremity was prepared.

The fracture line was opened with a longitudinal incision from the lateral. The fracture ends were reached. The whole of the femur medulla was seen to be closed and sclerotic. The medulla was then drilled and opened with a series of reamers. During this process, the drill bit was broken twice and one of the broken drill bits remained in the medullary canal. The fracture was then reduced and fixation was made with one antirotation wedge PFN screw (TST ${ }^{\circledR}$, Turkey). One lag screw and one antirotation wedge were advanced in the femoral neck, and the distal screw was locked with two nails. Throughout the operation, particularly during the drilling, extreme difficulties were experienced.

Fluoroscopy checking was applied and the operation was concluded. On the radiograph taken on postoperative Day 1, the lag screw was seen not to be fixed in the femoral head (Figure 2), so revision surgery was planned for the patient. On postoperative Day 4, the patient was again taken in for surgery, the PFN was removed and fixation was made with a proximal femur plate (TST). As there was no good bone contact in the trochanteric region during the operation, allograft of 30 cc corticocancellous chips was applied. During the operation, the drill bit broke once. Under fluoroscopy control, the operation was terminated (Figure 3). On postoperative Day 8 , a dense seropurulent discharge started. The laboratory test

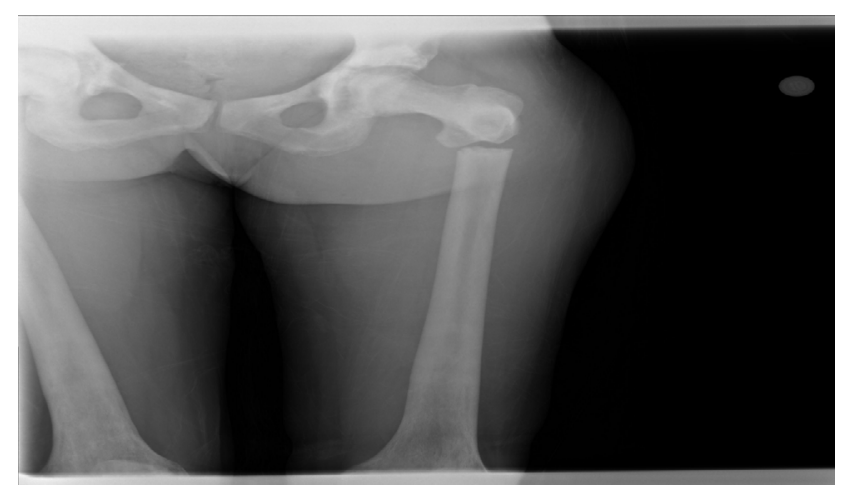

Figure I An anteroposterior view of the right hip at the time of initial presentation shows displaced subtrochanteric fracture and the osteosclerotic appearance of the osteopetrotic bone. values were: C-reactive protein (CRP), 13.2 and erythrocyte sedimentation rate, $85 \mathrm{~mm} / \mathrm{s}$. In the culture antibiogram which was applied, klebsiella pneumoniae proliferation was determined. After consultation with the infectious diseases department, treatment was started with the sensitive antibiotic imipenem silastatin sodium $4 \times 500 \mathrm{mg}$ intravenous (IV).

As the discharge continued, debridement was performed twice, on days 10 and 15 after the second operation. During the debridements, deep tissue cultures were taken. All the allografts were removed. In both debridements, irrigation with $3000 \mathrm{cc}$ of pressurized saline was performed. Following the debridements, the discharge recovered and the patient was discharged with oral antimicrobial treatment. At the 3- and 6-month follow-up examinations, there were no abnormalities in the laboratory test values but union was not observed on the direct radiographs. Findings of bone union started to appear at the postoperative 9-month follow-up examination. At the postoperative 12 th month examination, union of the fracture was observed (Figure 4), but in the distal of the incision

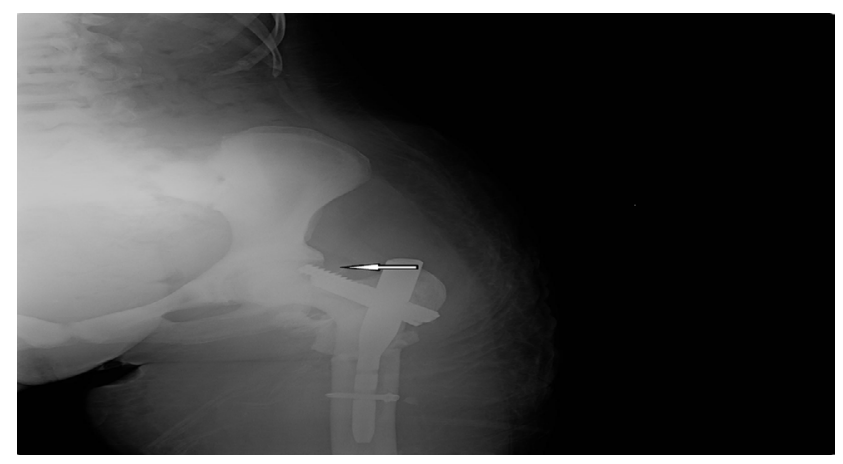

Figure 2 Postoperative radiograph after proximal femoral nailing. White arrow shows malposition of the lag screw.

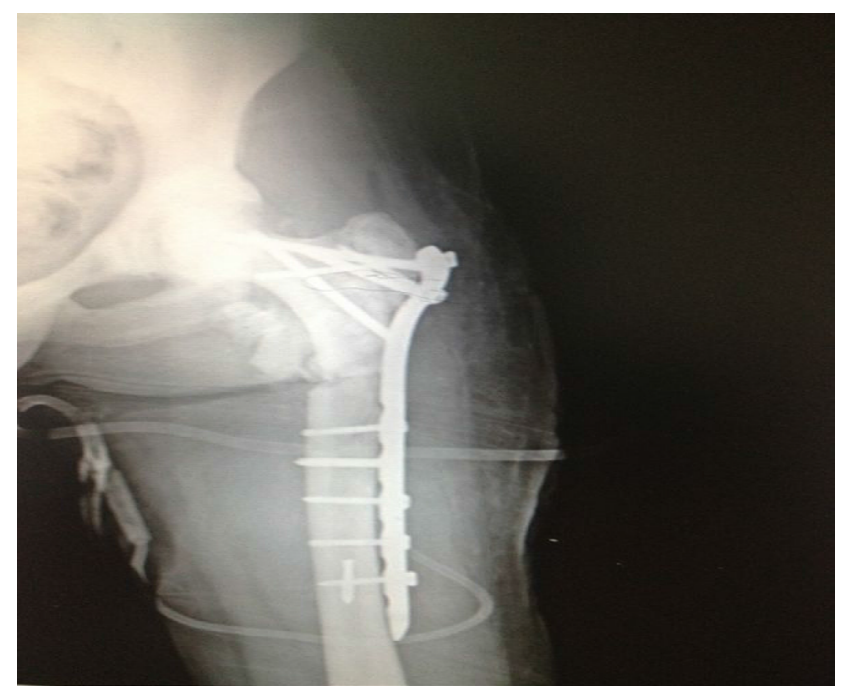

Figure 3 Postoperative radiograph after revision operation with proximal femoral anatomic plate. 


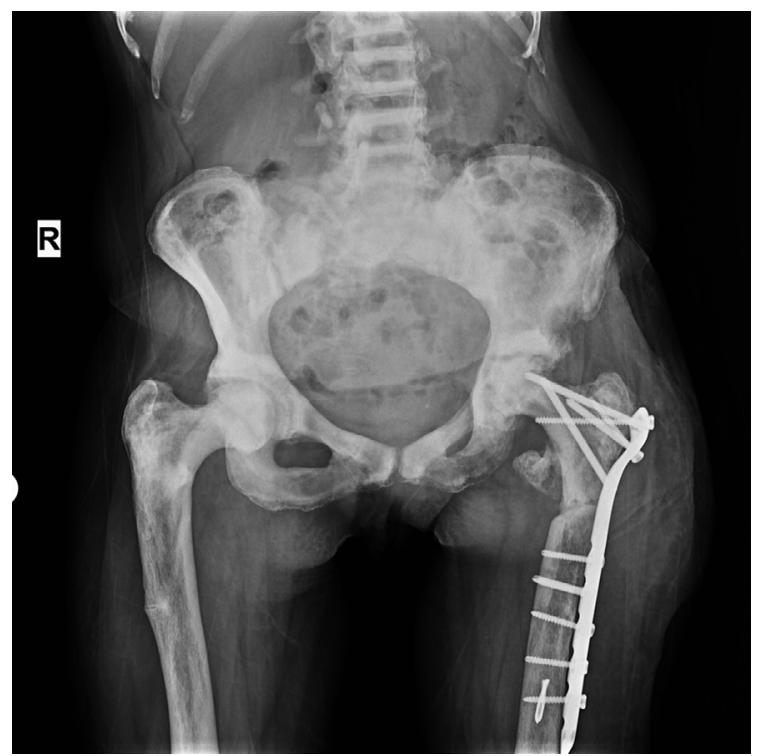

Figure 4 Postoperative twelfth month anteroposterior view, union of the fracture was observed.

line, a fistula opening and discharge were determined. The proximal femur plate was removed and extensive debridement was applied.

However, the drill bit could not be removed from the intramedullary region (Figure 5). In the culture taken, K pneumoniae production was again determined, so IV antibiotic treatment was started (imipenem cilastatin $4 \times 500 \mathrm{mg}$ ). When the discharge stopped and the laboratory values returned to normal, the patient was discharged with a 6-week course of oral antibiotics. When the oral antibiotic treatment finished, the patient presented again with fistula opening and wound site discharge. Extensive debridement was again performed and by opening a window in the lateral femur, the broken drill bit was removed. Following this operation, antibiotic treatment of 6 weeks IV followed by 6 weeks oral was administered. After finishing the antibiotic treatment, the CRP and sedimentation values were found to be normal at three polyclinic follow-up examinations at 1-month intervals. The patient was again evaluated at the final follow-up examination 8 months postoperative to the last operation. Direct radiographs were taken (Figure 6). The sedimentation and CRP values were normal. There was no discharge from the wound site. The patient was able to ambulate with a single crutch and was pain-free. Written informed consent was obtained from the patient for this publication and the figures.

\section{Discussion}

There is limited information in the literature related to fractures seen in patients with osteopetrosis and their treatment methods, and that which is available is generally in the form of case presentations. ${ }^{2-6}$ In osteopetrotic patients, the

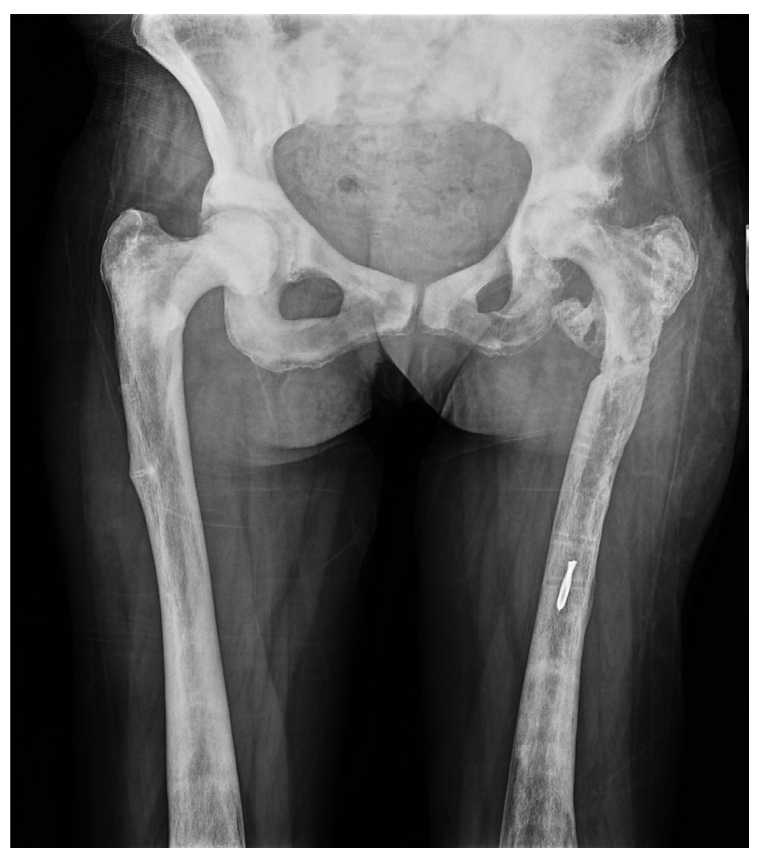

Figure 5 Anteroposterior view after the proximal femur plate was removed. The drill bit could not be removed from the intramedullary region.

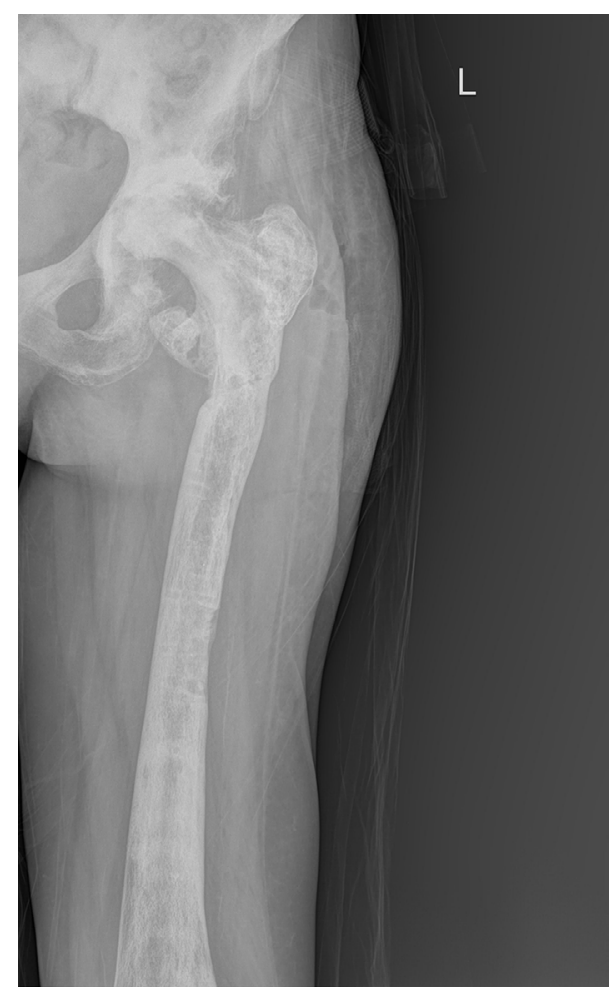

Figure 6 The last control radiograph of the patient.

proximal femur is the most common location of fractures. ${ }^{3}$ In the treatment of this type of fracture, intramedullary nailing, dynamic hip screws (DHS), or locked anatomic plate can be used..$^{1-4}$ The aim of this paper was to present and discuss the treatment method applied to a patient with osteopetrosis tarda who developed infection following revision surgery 
with proximal femoral plate for the unsuccessful previous surgery of PFN of a fracture in the proximal femur.

The cases presented in the literature related to osteopetrotic proximal femoral fracture are generally in the form of case reports, presenting the difficulties experienced during surgery and union of the fracture. There are even fewer case reports related to infection accompanying a fracture.

Regardless of the fixation material used, fixation of an osteopetrotic proximal femoral fracture is difficult and is open to complications. Kumbaraci et al ${ }^{4}$ reported successful results from fixation made with PFN in a case of bilateral femur fracture. However, it was stressed that opening the intramedullary canal was difficult and care must be taken in respect of drill bit breakage. Cadosh et $\mathrm{al}^{5}$ reported fixation of a proximal femoral fracture with intramedullary femoral nailing but the drill bit was broken during reaming of the femur. Aslan et $\mathrm{al}^{2}$ used proximal femoral plate in two separate cases, and full union was obtained with no development of implant failure. However, technical difficulties were experienced during the operations and drill bits were broken. In the current case, drill bits were broken in both the first operation and subsequent revision while applying fixation with the proximal femoral plate.

Breck et al reported that using an electrical drill to open the medullary canal in osteopetrotic bone made it easier to open the medulla. ${ }^{6}$ Sen et al recommended using a metalcutting drill bit to overcome the problem of drill bit breakage. Thus, the drilling was easier and thermal necrosis was prevented. ${ }^{7}$ Both these studies stated that extra care must be shown to prevent the breakage of drill bits. ${ }^{6,7}$

In the internal fixation of proximal femur fractures, intramedullary implants, DHS, dynamic condylar screws (DCS), proximal femur plate, and conventional plate-screw systems can be used. Each implant has its own advantages and disadvantages. These are all valid for osteopetrotic patients, but irrespective of the implant used, the risks of implant failure are higher than in normal bones. ${ }^{8-11}$ Chabra et al reported that implant failure developed in two patients where fixation was applied with conventional plate-screw. ${ }^{8}$ Ashby also reported treatment of two subtrochanteric fractures in a patient with osteopetrosis, where one of the two fractures eventually required total hip arthroplasty after initial device failure. ${ }^{9}$ Furthermore, Ramiah et al presented successful revision with total hip prosthesis following plate-screw fixation failure in an osteopetrotic femoral neck fracture. ${ }^{11} \mathrm{In}$ the current case, PFN was revised. However, in the current case, the revision was performed due to a technical error associated with incorrect interpretation of the intraoperative fluoroscopy image rather than implant failure. The error was considered to have been due to the fluoroscopy imaging not having been performed from an ideal angle as the patient was in the lateral decubitus position.

The fracture healing mechanism in osteopetrosis is the same as in normal bones, although the time to fracture healing is longer. The duration of fracture healing may be up to 1 year. ${ }^{10,12}$ Kumar et $\mathrm{al}^{10}$ reported union of a proximal femoral fracture treated with DHS in 11 months; Kumbaraci ${ }^{4}$ reported 11 months with PFN; and Aslan ${ }^{2}$ obtained union in 12 months in two patients treated with plate-screw. The time to union in the current case was 12 months.

There are few reports in literature related to the use of graft in osteopetrotic fractures. Rafiq reported successful results with allograft and bone morphogenetic proteins (BMP) used in an osteopetrotic humerus nonunion. ${ }^{13}$ Golden et al treated a subtrochanteric femoral fracture with (DCS) and recommended the use of osteoconductive BMP to accelerate bone union. ${ }^{14}$ In the current case, chips allograft was used for a defect in the femur medial cortex after the second operation. However, as acute infection developed, all the allograft was removed. Therefore, it was not possible to make any comment on the effect of the allograft used on the fracture union.

Just as fracture union is difficult in osteopetrotic patients, there is a predisposition to infection. If infection develops after an operation, treatment is difficult and prolonged. The main principle in the treatment of infection is not differed from that of normal tissues. Antimicrobial treatment directed to the agent, debridements, and removal of all implants and foreign bodies are included in treatment. ${ }^{11}$ However, intervention in infection in the osteopetrotic patient group must be more radical and applied with more patience because in these types of patients, both disrupted local vascularization of the bone and the host resistance to infection are low. ${ }^{11,15}$ There are diverse microbial agents such as staphylococcus aureus, $k$ pneumoniae, enterococcus spp, and gemella morbillorum. ${ }^{10-15}$ In a case presented by Rolauffs et al following a series of debridements in a patient with an osteopetrotic femoral neck fracture where chronic osteomyelitis developed, it was necessary to perform girdlestone resection arthroplasty. ${ }^{15}$

Manzi et al treated a patient with an infected intertrochanteric femoral fracture with two-stage total hip prosthesis after removal of the implant. For a period of almost 1 year, the authors struggled with the infection. ${ }^{16}$ In the current case, as there was no union of the fracture, it was initially attempted to apply the treatment without removal of the implant with antimicrobial treatment directed to the agent and a series of debridements. In this period, although the CRP and sedimentation levels of the patient dropped to normal levels, when 
the antimicrobial treatment was terminated, the infection was seen to flare up again. Until the proximal femoral plate was removed and later the drill bit from the intramedullary region, the infection was not seen to completely recover.

The current case underwent a total of six operations; $2 \times$ fracture fixation, $2 \times$ debridement, $1 \times$ implant removal, and $1 \times$ drill bit removal. This was due to the complications experienced during the first operation and the subsequent infection. In addition, breaking of the drill bit in the intramedullary region when removing the proximal femoral plate resulted in an extra operation being performed for its removal.

In conclusion, from the previous cases reported in the literature and the current case, it must be kept in mind that the treatment of fractures in osteopetrotic patients will be difficult; healing will take a long time, various intraoperative problems could be experienced such as the breakage of drill bits, and there is a greater risk of postoperative infection in these fractures. We think that the best option in the surgical treatment of such patients should be to endure, spare drill bits should be taken, and absolutely to the general rules of sterilization should be followed.

We suggest that whichever implant is used, intraoperative fluoroscopy images must be carefully evaluated. Patience must be applied when opening the medullary canal during the operation. If infection develops, it must not be taken lightly and the necessity of serial debridements and removal of all implants must not be ignored.

\section{Disclosure}

The authors report no conflicts of interest in this work.

\section{References}

1. Gupta RK. Long bone fractures in osteopetrosis: awareness of primary pathology and appropriate pre-operative planning necessary to avoid pitfalls in fixation. Injury Extra. 2005;36(3):37-41.
2. Aslan A, Baykal YB, Uysal E, et al. Surgical treatment of osteopetrosisrelated femoral fractures: two case reports and Literature Review. Case Rep Orthop. 2014;10.1155:2014.

3. Gupta R, Gupta N. Femoral fractures in osteopetrosis: case reports. J Trauma. 2001;51(5):997-999.

4. Kumbaraci M, Karapinar L, Incesu M, Kaya A. Treatment of bilateral simultaneous subtrochanteric femur fractures with proximal femoral nail antirotation (PFNA) in a patient with osteopetrosis: case report and review of the literature. J Orthop Sci. 2013;18(3): 486-489.

5. Cadosch D, Gautschi OP, Brockamp T, Zellweger R. Osteopetrosis - a challenge for the orthopaedic surgeon. SAfr J Surg. 2009;47(4):131-133.

6. Breck LW, Cornell RC, Emmett JE. Intramedullary fixation of fractures of the femur in case of osteopetrosis. J Bone Joint Surg Am. 1957;39(6):1389-1394.

7. Sen RK, Gopinathan NR, Kumar R, Saini UC. Simple reproducible technique in treatment for osteopetrotic fractures. Musculoskelet Surg. 2013;97(2):117-121.

8. Chabra A, Westerlund LE, Kline AJ, McLaughlin R. Management of proximal femoral shaft fractures in osteopetrosis: a case series using internal fixation. Orthopedics. 2005;28(6):587-98

9. Ashby ME. Total hip arthroplasty in osteopetrosis: a report of two cases. Clin Orthop Relat Res. 1992;(276):214-21.

10. Kumar D, Jain VK, Lal H, Arya RK, Sinha S. Metachronous bilateral subtrochanteric fracture of femur in an osteopetrotic bone: a case report with technical note. J Clin Orthop Trauma. 2012;3(2):103-106.

11. Ramiah RD, Baker RP, Bannister GC. Conversion of failed proximal femoral internal fixation to total hip arthroplasty in osteopetrotic bone. J Arthroplasty. 2006;21(8):1200-1202.

12. Bhargava A, Vagela M, Lennox CM. Challenges in the management of fractures in osteopetrosis. Review of literature and technical tips learned from long-term management of seven patients. Injury. 2009;40(11):1167-1171.

13. Rafiq I, Kapoor A, Burton DJ, Haines JF. A new modality of treatment for non-united fracture of humerus in a patient with osteopetrosis: a case report. J Med Case Rep. 2009;3:15-18.

14. Golden RD, Rodriguez EK. Management of subtrochanteric femur fractures with internal fixation and recombinant human bone morphogenetic protein-7 in a patient with osteopetrosis: a case report. $J$ Med Case Rep. 2010;4:142.

15. Rolauffs B, Bernhardt TM, von Eiff C, Hart ML, Bettin D. Osteopetrosis, femoral fracture, and chronic osteomyelitis caused by Staphylococcus aureus small colony variants (SCV) treated by girdlestone resection 6-year follow-up. Arch Orthop Trauma Surg. 2002;122(9-10): $547-550$.

16. Manzi G, Romanò D, Moneghini L, Romanò CL. Successful staged hip replacement in septic hip osteoarthritis in osteopetrosis: a case report. Musculoskelet Disord. 2012;13:50.
International Medical Case Reports Journal

\section{Publish your work in this journal}

The International Medical Case Reports Journal is an international, peer-reviewed open-access journal publishing original case report from all medical specialties. Previously unpublished medical posters are also accepted relating to any area of clinical or preclinical science. Submissions should not normally exceed 2,000 words or

\section{Dovepress}

4 published pages including figures, diagrams and references. The manuscript management system is completely online and includes a very quick and fair peer-review system, which is all easy to use. Visit $\mathrm{http}: / /$ www.dovepress.com/testimonials.php to read real quotes from published authors. 